\title{
Impact of Interactive Digital-Based Hepatitis C Education on Self-Management and Quality of Life of Damanhour University Students Having Hepatitis C.
}

\author{
Reem Bassiouny Mahmoud El Lassy ${ }^{1^{*}} \quad$ Amel Attia Abd El Gaffar Moustafa ${ }^{2}$ \\ 1. Assistant Professor, Community Health Nursing Department, Faculty of Nursing, Damanhour University, \\ Egypt \\ 2. Lecturer, Community Health Nursing Department, Faculty of Nursing, Damanhour University, Egypt
}

\begin{abstract}
Background: Chronic hepatitis $\mathrm{C}$ virus (HCV) infection is a major public health crisis and currently is the most frequent cause of liver related morbidity and mortality which caused 1.34 million deaths in 2015 globally. Infected individuals experience a variety of physical and psychological symptoms, functional limitations and impaired quality of life as a result of having HCV. Aim of study: is to assess the impact of Interactive Digital-Based Hepatitis C Education on Self-Management and Quality of Life of Damanhour University Students Having Hepatitis C. Hypothesis: University students having Hepatitis $C$ who engage in interactive digital-Based Hepatitis $\mathrm{C}$ education demonstrate greater improvement in Self-Management and quality of life than those who are not. Material and Methods: Quasi-experimental pre/post-test research design. Settings: The study was carried out in the medical health insurance clinic affiliated to Damanhour University. Subjects: the total sample was 36 students having Hepatitis C. Tools: Data was collected through using students' knowledge about HCV Structured Questionnaire Sheet, Generic health-Related Quality Of Life Scale, Disease-Specific Health-Related Quality Of Life questionnaire, Hepatitis C Self-Management Profile Scale and Satisfaction with Interactive Digital-Based Hepatitis $\mathrm{C}$ educational program scale. Results: More than half of the intervention group (55.6\%) aged more than 20 years with a mean age of $20.9 \pm 2.01$ years, and more than one third of the control group (38.9\%) with a mean age of $19.4 \pm 2.17$ years. Above two thirds of the intervention and control groups, $(66.7 \%$, and $50.0 \%$ respectively) were males. Social networks and Websites, reported as the main source of information about hepatitis $\mathrm{C}$ by less than half of the intervention group (44.4\%), and more than two thirds of the control group (66.7\%). Only $11.1 \%$ of the intervention group had good knowledge level at pre program, with mean score of $7.08 \pm 3.01$ compared to less than two thirds of them (61.1\%) in post program. Significant differences was observed between intervention group at pre and 3 months post program implementation $(\mathrm{t} 1=4.25, \mathrm{P}=0.002)$. Interactive Digital-Based Education showed a significant impact on the intervention group's practices in different areas of Hepatitis $\mathrm{C}$ self-management. It is evident that, statistical significant correlation was found between intervention group's satisfaction with the program and total score of self-management practices and quality of life in post program. Conclusion and Recommendations: Interactive Digital-Based Education on Self- Management of Hepatitis $\mathrm{C}$ had positive impact on $\mathrm{HCV}$ outcomes including improvement in Hepatitis $\mathrm{C}$ knowledge, self-management practices and quality of life. In addition, it plays a significant role in improving Hepatitis $\mathrm{C}$ control, and motivates the students to adopt healthy lifestyle. The overall results revealed that, university students' satisfaction with Interactive Digital-Based Hepatitis $\mathrm{C}$ educational program was high. Therefore, use interactive technology to disseminate hepatitis $\mathrm{C}$ education messages to young people, including WhatsApp, Web Based education, etc. Also, Develop University $\mathrm{HCV}$ Online platform for young people having Hepatitis $\mathrm{C}$ who need to receive age-appropriate Hepatitis C education.
\end{abstract}

Keywords: Interactive Digital-Based education, Self-management, Hepatitis C, Health-Related Quality Of Life. DOI: $10.7176 / \mathrm{JHMN} / 66-02$

Publication date:September $30^{\text {th }} 2019$

\section{Introduction}

Chronic hepatitis $\mathrm{C}$ virus (HCV) infection is a major public health crisis where its seroprevalence had an estimated $2.8 \%$ increase over the last decade that affects approximately 170-200 million individuals globally, with 3-4 million new infections occurring annually. Currently, it is the most frequent cause of liver related morbidity and mortality which caused 1.34 million deaths in 2015. ${ }^{(1-4)}$ Additionally, most HCV-infected individuals experience a variety of physical and psychological symptoms, functional limitations, and impaired quality of life as a result of having HCV and diminished abilities in the areas of concentration, attention, verbal learning, working memory, and psychomotor performance. ${ }^{(5,6)}$ Nearly three quarters of infected individuals are living in middle income countries. HCV genotype 1 is the most prevalent worldwide (49.1\%), followed by genotype $3(17.9 \%), 4(16.8 \%)$ and $2(11 \%)$. Genotype 4 was most common (71\%) in North Africa and the Middle East, but when Egypt was excluded, it accounted for $34 \%$, while genotype 1 accounted for $46 \%$ of infections across the same region. ${ }^{(1,7)}$

In Egypt, the situation is very critical, $\mathrm{HCV}$ is a foremost public health problem and well thought-out an 
endemic. ${ }^{(8)}$ Egypt has the highest and devastating prevalence of hepatitis $\mathrm{C}$ virus (HCV) in the world, amounting to $14-20 \%$ in $15-59$ year age group, $10 \%$ chronic infection, and $90 \%$ genotype $4 .{ }^{(9)}$ In Egyptian Health Issues Survey (EHIS) 2015, a significant reduction of $32 \%$ and $29 \%$ in HCV antibodies and HCV RNA positive individuals was reported respectively reaching $10 \% \mathrm{HCV}$ seroprevalence and $7 \%$ viremia, in the same age group. $(7,10)$ In Egypt, the wave of increased HCV- related morbidity and mortality is likely due to the wide spread availability of injectable therapies and the illicit use of injectable drugs. Major known modes of transmission include intra-familial transmission, direct blood contact, mother to child, organ transplant, injectable treatment for schistosomiasis, needle-stick injuries, medical and dental procedures, injection drug use, and sharing contaminated materials like razors and shaving kits ${ }^{(11)}$. No vaccine exists to prevent $\mathrm{HCV}$ infection, and while treatment has improved considerably over the years, therapy is only partially effective and is afflicted by side effects that contribute to treatment failure. Thus the prevention of primary HCV infection is a public health issue of major importance $^{(11,12)}$.

Some Chronic Hepatitis $\mathrm{C}(\mathrm{CHC})$ patients deliberate their disease shameful due to the social stigma that hepatitis $\mathrm{C}$ infection is assimilated through drug abuse, including narcotics, and risky sexual behaviors. Studies had proposed that these patients are usually concerned about the possibility that they may infect others around them owing to the lack of knowledge on the disease process of Hepatitis C. ${ }^{(13,14)}$ Deficiency of knowledge and awareness about Hepatitis $\mathrm{C}$ in the community habitually leads to distortion, missing of opportunities for prevention and treatment, and stigmatization of infected populations. ${ }^{(14)}$

In hepatitis, the presence of the virus in the liver cells causes the immune system to attack the liver, resulting in inflammation and impaired function. Acute infection may occur with limited or no symptoms, or may include symptoms, such as jaundice, dark urine, extreme fatigue, nausea, vomiting, and abdominal pain. ${ }^{(15)}$ Moreover, the most common symptoms cited by patients with hepatitis $\mathrm{C}$ and that impact upon their quality of life are fatigue, depression, anxiety, cognitive impairment, painful muscle and joint symptoms. (16) Additionally, antiviral medications typically used to battle hepatitis $\mathrm{C}$ may cause sexual dysfunction and decreased libido. Sexual dysfunction is the most frequently encountered side effect of many antidepressant medications used to treat the depression and anxiety associated with combination treatment for HCV. ${ }^{(17)}$ Accordingly; they may have bad relationships with their family or be isolated from society because of physical tiredness or feelings of powerlessness. As such, Chronic HC is originated to widely affect the patients' personal and family lives and even the society at large, representing that efforts are desired to recover their Health-related quality of life (HRQOL) (14)

The Health-related quality of life is a concept that refers to the effects of health on the quality of life. Considering that HRQOL is an indicator of the health conditions of patients with $\mathrm{CHC}$, it can be useful in the establishment or evaluation of nursing plans for these patients. ${ }^{(18)}$ Previous studies have demonstrated a significant decreased quality of life (QOL) in patients suffering from hepatitis, even in the absence of cirrhosis, and that successful treatment of HCV is associated with an improvement in HRQOL. A study done in Australia revealed that chronic hepatitis $\mathrm{C}$ and combination therapy had an enormous impact on the lives of the patients, their partners and families. ${ }^{(19)}$

Increase in the number of people living with chronic illnesses has been met with a resultant swing in healthcare towards an emphasis on self-management for patients living with chronic illnesses. Lorig and Holman (2003) propose that self-management tasks fall into one of three categories: 1. Medical management, which involves behaviors such as adhering to one's medication; 2. Role management, which involves recognizing one's limitations and engaging in less strenuous activity; and 3. Emotional management, which involves coping with the psychological correlates of disease such as anxiety and/or depression. They also list five skills central to selfmanagement including problem solving, decision-making, resource utilization, forming patient- health-care providers' partnerships, and taking action. Problem solving involves defining a problem, generating potential solutions, implementing a solution, and evaluating it. Decision-making involves choosing a solution and is based on having enough appropriate information. Self-management can be conceived of as an important proximal outcome of patient education that is a necessary prerequisite for the achievement of more distal goals as course of disease, quality of life or social participation. Self-management interventions are one option for advancing improved HCV knowledge and health-related quality of life (HRQOL). ${ }^{(20,21)}$

It is now well established that HCV is of universal importance, affecting all countries, leading to a major global health problem that requires widespread active interventions for its prevention and control ${ }^{(22)}$. Education is the cornerstone supporting the framework of self-management programs that teach patients to identify and prioritize their own problems, take appropriate action, and enlist the support needed to solve these problems in collaboration with health care providers and family. Self-management programs have been effective in many disease groups, cultures, and countries. Despite the need for such approaches, research on hepatitis selfmanagement is limited ${ }^{(23)}$.

Learning self-care behaviors is an important way to enhance self-esteem and autonomy, and to empower the young people with $\mathrm{HCV}$ to become a responsible individual. ${ }^{(24)}$ Information and communication technologies 
(ICT) have evolved to be typical elements in all aspects of life. The utility of advanced communication technology in health care is in increasing access to health care services, and broadening availability of resources, even among underserved populations. The use of technology has revolutionized the way patients are educated about health. One emerging and promising area to facilitate patient engagement at a low cost is the provision of support for patient through digital media technologies such as the Internet or smartphones. Digital health technologies are described as promoting communication between healthcare providers and patients, encouraging lay people to engage in preventive health activities and improving patient adherence to treatment protocols and their selfmanagement of chronic diseases. It has been gaining strong support as evidence builds of its effectiveness for HCV management and education. ${ }^{(25)}$ Moreover, digital-based education can assist with the provision of tailored and personalized education, feedback, and goal setting, thereby facilitating patient-centered care and communication and educate people with $\mathrm{HCV}$ in managing their own condition ${ }^{(26)}$.

The nurse plays an integral role within the prevention, diagnosis and management of HCV. Nurses can increase skills, knowledge and confidence, as well as support and empower the person with HCV to self-manage their condition and lessen the chances of developing further health complications ${ }^{(27)}$. With that evolution, new roles emerge and provide fertile ground for nurses to apply their skills in different ways. Moreover, emerging new technologies, such as Web 2.0 innovations, smart phones, social media and data management systems, could provide solutions to complex health-care issues ${ }^{(28)}$. Currently, nurses use tele-nursing for all practices of nursing which is especially useful for people with HCV who have problems of far distance to the health care clinics or need a long time waiting for visiting a doctor ${ }^{(29)}$.

\section{The aim of the study:}

Is to assess the impact of Interactive Digital-Based Hepatitis C Education on Self-Management and Quality of Life of Damanhour University Students Having Hepatitis C.

Research Hypothesis:

University students having Hepatitis $\mathrm{C}$ who engage in interactive digital-Based Hepatitis $\mathrm{C}$ education demonstrate greater improvement in Self-Management and quality of life than those who are not.

\section{Material And Methods}

\subsection{Material:}

\subsubsection{Research design:}

Quasi-experimental pre/post - test study was adopted to conduct this study.

2.1.2 Study setting:

The study was carried out in the medical health insurance clinic affiliated to Damanhour University.

\subsubsection{Subjects:}

Students who were attended the medical clinic for treatment of Hepatitis C Virus.

The students included in the study fulfilled the following eligibility criteria:

1- Confirmed diagnosed for positive Hepatitis C.

2- Those did not attend any Hepatitis $\mathrm{C}$ educational program prior to the study.

3- Free from other chronic diseases.

4- Possessed a personal computer at home or smart Mobile phones.

5- Willing to participate 3 months in interactive digital-based Hepatitis C education.

2.1.4 Sampling technique:

Purposive sample of students having positive Hepatitis $\mathrm{C}$ test

2.1.5 Sample size:

Damanhour University in a collaboration with CARITAS Egypt have an initiative strategy which was implemented yearly since 2016 for screening university students for Hepatitis C. The total of 49.873 students were affiliated to ten faculties at Damanhour University. According to medical records (2017), 45 students were confirmed diagnosed for Hepatitis $\mathrm{C}$ and received treatment. Those students with Hepatitis $\mathrm{C}$ have records and regularly attend the clinic for follow up and management. A total of 40 students fulfilled eligibility criteria and agreed to participate in the study. Then, pilot study was carried out on 4 students randomly selected and excluded from the study. The total study sample $(\mathrm{N}=36)$ was randomly assigned to one of two groups, 18 students was control group and the other 18 students was intervention group. The intervention group received interactive digital-based hepatitis $\mathrm{C}$ self- management education program, while the control group received routine care.

\subsubsection{Tools for data collection:}

Four tools were used to collect the required data for the study;

Tool (I): Students' Knowledge about HCV Structured Questionnaire Sheet:

This tool was settled by the researchers after reviewing the related current national and international literature. This questionnaire is alienated into four sections to collect the following data:

Section 1: Socio-demographic characteristics

This section includes socio demo-graphic characteristics: age, gender, educational level, marital status, place of 
residence, parents' education, parents' occupation, and monthly income.

Section 2: Students' knowledge about HCV

This section is made up of 15 items includes general knowledge about HCV, mode of transmission and how to prevent it, the stage of illness, symptoms, prevention of progression, factors contributes further damage of liver, protection from HAV and HBV, healthy diet, substance abuse treatment; safer injection practices; and how to obtain harm-reduction services, common hepatotoxic medications, signs of cirrhosis, liver failure, and hepatocellular carcinoma and options for antiviral treatment. A score of (1) was given to Yes, a score of (0) for No/Not Sure. The maximum score was ranged from 0-15 points and the total knowledge score was categorized as:

- $\quad<50 \%$ (less than 7.5$)=$ Poor level of knowledge.

- $\quad 50 \%<75 \%(7.5$ to less than 11.25$)=$ Fair level of knowledge.

- $75 \%-100 \%(11.25-15)=$ Good level of knowledge.

Section 3: Students' sources of hepatitis $\mathbf{C}$ information as physician, nurse, media, social networks/Websites Tool (II): Generic health-related quality of life scale

HRQOL is a systematic tool to assess quality of life of HCV patients. (SF-36) is an instrument universally used to assess HRQOL. (SF -36) questionnaire is made up of 25 questions and 36 items. The items of (SF - 36) approved by Martino, $(1997)^{(14,30)}$. It consists of a total of 36 items across 8 domains. The physical domains include physical functioning (10 items), physical role limitations (4 items), pain ( 2 items), and general health (6 items). The mental domains comprise vitality (4 items), social functioning ( 2 items), emotional role limitations ( 3 items), and mental health $(5 \text { items })^{(13,14)}$.

All items were scored from 1-3, in which ( 3 indicating all of the time, 2 indicating some of the time and 1 indicating none of the time) total generic HRQOL score was obtained by summing the scores of the eight domains. All raw scores were transformed to a $0-100$ score using the following formula: ${ }^{(14,31)}$

Transformed score $=\underline{(\text { actual raw score }- \text { lowest possible raw score })} \times 100$

Possible raw score range

Higher score indicates better Generic Health-Related Quality Of Life (HRQOL).

Tool (III): Disease-Specific Health-Related Quality of Life Questionnaire

The hepatitis quality of life questionnaire used to detention all the possible impact of the $\mathrm{HCV}$ on the physical, psychological, social and spiritual aspects of the respondent during the course of a disease ${ }^{(14,20)}$. The HCV specific Health-Related Quality Of Life signifies of 35 items. These questions are allocating into 4 domains Physical (16 items), Psychological (7 items), Social (8 items) and Spiritual impact of the disease (4 items). All items were scored as stated by 3 points Likert scale from 1-3, in which (3 indicating all of the time, 2 indicating some of the time and 1 indicating none of the time) scores of each of the four domains was calculated by summing the scores of its items. Total specific HRQOL score was achieved by summing the scores of its domains. All raw scores were transformed to a $0-100$ score using the following formula ${ }^{(14)}$ :

Transformed score $=\underline{(\text { actual raw score }- \text { lowest possible raw score })} \times 100$

Possible raw score range

Tool (IV): The Hepatitis C Self-Management Profile Scale:

It is a structured questionnaire developed by the researcher to assess self-management practices among students with Hepatitis C. It consists of 25 items measuring 5 domains: diet, hydration, exercise, maintain healthy weight, mental health, risky behaviors, investigation, follow up, adherence to treatment, barriers to HCV care and implementing appropriate control and prevention measures.. A score of (2) was given to the correct complete answer, a score of (1) for correct but incomplete answer and a score of (0) for the wrong or missed answers. The maximum score was ranged from $0-50$ points and the total practices score was categorized as follows;

- $\quad<50 \%$ (less than 25 ) $=$ Poor level of practice.

- $50 \%<75 \%(25$ to less than 37.5$)=$ Fair level of practice.

- $75 \%-100 \%(37.5-50)=$ Good level of practice.

Tool (V): Satisfaction with Interactive Digital-Based Hepatitis C educational program scale:

This evaluation tool was developed by the researcher to evaluate the satisfaction with the educational program. It was used to assess the program along multiple dimensions: ease of use; content clarity and comprehensiveness; organization; applicability; usefulness; effectiveness; attractiveness; motivation for self -management; and longterm adherence. This tool was composed of 15 items on a 5-point Likert scale ranging from strongly disagree to strongly agree. For each statement, a score of 1-5 was assigned to responses. Summing the score of the scale items and dividing by the number of items in the scale was computed the score. Thus, the total scale scores range from

1 to 75 . The scale score was calculated as follows;

- $\leq 50 \%$ (less than 38$)=$ dissatisfied

- $51 \%<75 \%(38$ to 56$)=$ neutral.

- $75 \%-100 \%(56-75)=$ Satisfied. 


\subsection{Methods:}

The study was executed according to the following steps:

- Permission to conduct the study in the selected setting was obtained after explanation of the aim of study.

- Tool I of data collection was settled by the researchers after extensive review of relevant and current literature. Tool I, IV and V were checked for content validity by the jury of three experts in the field and tools reliability was tested by the Cronbach's alpha coefficient test. Its result was $0.76,0.881$, and 0.910 respectively, which indicates an accepted reliability of the tool. Tool (II and III) are a standardized which is used by the researchers (Generic health-related quality of life scale and Disease-Specific Health-Related Quality Of Life).

- Pilot study: was carried out on a sample of (4) Hepatitis C students not included in the study sample to ascertain the clarity and applicability of the tools, according to their response the tools were modified.

- Medical clinic is working 3 days/week as one shift. The researcher set an appointment date to meet the study sample at the clinic, and to complete the questionnaire at assessment phase.

- Researchers obtained students' phone number to create WhatsApp broadcast for the intervention group and set an appointment date for evaluation of the control group.

- Data collection phase: The data collection phase took about 1 months at November 2018 to assess students' knowledge about hepatitis c, self-management practices, and quality of life.

- January 2019 till March 2019 to implement the program over a period of three months.

- $\quad$ Evaluation of the program was conducted until June 2019

- Program: Interactive Digital-based Hepatitis $\mathrm{C}$ educational program was applied according to the following phases:

\section{A. Assessment phase:}

The questionnaire distributed to be completed by all selected students control and intervention groups as pre-test. The objectives and the content of questionnaire were explained to them. Researcher obtained students' mail address and telephone number from each student in order to follow them up during 3 months of intervention; also to encounter any problems during application of the program.

\section{B. Planning phase:}

Interactive digital-based Hepatitis $\mathrm{C}$ educational program was developed by the researchers for the intervention group. The content of the program was based on review of literature, results of assessment as well as characteristics of students, their needs and according to the following steps:

\section{Setting program objectives.}

The aims of the program are to:

- Help students to acquire health knowledge which is interrelated with self- management and quality of life of Hepatitis C students.

- Improve student's self-management practices in relation to Hepatitis C.

2. Determination of specific objectives: at the end of the program, students will be able to: recognize the concept of Hepatitis C, identify diagnostic measures of Hepatitis C, determine risk behaviors, identify Hepatitis $\mathrm{C}$ complications, implement effective Hepatitis $\mathrm{C}$ therapy regimen, and describe methods of protection of other people.

3. Determining the content of the health education program: defining the content based on current literature and the results of the assessment phase, the researcher divided the subjects of the health education program into 12 subjects:

1. Function of liver

2. General knowledge about $\mathrm{HCV}$

3. Mode of transmission

4. Factors contributes further damage of liver

5. Signs and symptoms

6. Investigations done for diagnosis of the disease

7. Healthy diet

8. Exercise

9. Protection from risky behaviors

10. Treatment of HCV and follow up

11. Protection of other from having HCV

12. How to maintain mental, spiritual and sexual health

4. Designing the Interactive Digital-Based program: this step includes the following actions:

4.1. Designing of content presentation methods: Several interactive digital-based learning methods includes; website, e-mail, and whatApp were used to present the content of the program. The website was developed by using set of technical and instructional standards, which developed by web designer team. The researchers with the web designer selected a learning platform. A learning platform is a set of interactive online services that provide learners with access to information, and resources to support educational delivery and 
management through the Internet. Content is displayed after design scenario through written information accompanied by images, fixed and animated graphics as well as video clips. Additionally, researchers create a WhatsApp broadcast group to daily communicate with students.

4.2. Design of educational interaction patterns: in designing the program environment, the educational interaction opportunities are diversified, so that students can take advantage of the program's data, which includes: interaction between learner and content, interaction between learner and researchers.

4.3. Multimedia production: after the finalization of the scenario, the stage of converting this scenario into digital-learning resource presented through the website.

5. Validity of the program:

This phase aims to ascertain the validity of the health education program produced for the application and to conduct the experiment, which includes the following actions:

1. The researcher carried out the sequential review of the production processes, made the necessary adjustments and reviewed it, to ensure the quality of the production.

2. Web- based health education program was evaluated for its internal validation by obtaining the students and experts in the field of community health nursing, with an aim to:

○ Check links to the content of the health education program.

- Discovering technical problems in the design or production of the health education program. Accordingly, all appropriate solutions were taken into consideration.

- Ensure the suitability of the multimedia used with the research subjects.

$\circ$ Evaluate the final form of the design of the health education program as a whole.

- Confirm that the health education program for the Hepatitis $\mathrm{C}$ students has become a valid application.

C. Implementation phase:

- After completion of program development, the content of the designed program were uploaded to the web site. The website publication was done through sending website link through students' e-mail.

- Daily Short health messages were sent to all students of the intervention group through WhatsApp application. These messages includes important hepatitis $\mathrm{C}$ self-management practices and needed information. The researcher replied to any questions from the students to ascertain interactive learning.

D. Evaluation phase:

- Evaluation for the intervention group was conducted three months post program implementation through sending electronic posttest email by using tools: I \{Section 2$\}$, II, III, and IV) to determine impact of the program on enhancing students' knowledge, self-management practices and quality of life.

- $\quad$ Satisfaction with Interactive Digital-Based Hepatitis C educational program was evaluated using tool (V).

- Posttest was done for the control group through interviewing them at the clinic during regular follow up 3 months of the program completion by using the same tools: I \{Section 2\}, II, III, and IV.

Statistical analysis: Data were analyzed using the statistical package for social sciences (SPSS version 20) software. The level of significance selected for this study was $\leq 0.05$

The following statistical measures were used:

- Descriptive statistics: frequencies, percentages, arithmetic means, and standard deviation (SD) were used to describe the characteristics of the studied sample and main variables.

- Analytical statistics: ANOVA with Friedman's test, Pearson's R, and Paired t-test.

Ethical considerations: Written informed consent was obtained from students to participate in the study. The assurance of anonymity was addressed prior to a request for participation. Privacy and confidentiality were maintained during process of data collection. Ethically, WhatsApp broadcast group was created for students of the intervention group to ensure personal privacy during communication and this not ensured for WhatsApp group. In addition, Hepatitis $\mathrm{C}$ students of those at the control group were provided with the link of the program website. 


\section{Results}

Table 1. Distribution of the studied sample according to their personal characteristics.

\begin{tabular}{|c|c|c|c|c|c|}
\hline \multirow{2}{*}{ Personal Characteristics } & \multicolumn{2}{|c|}{ Intervention group $(n=18)$} & \multicolumn{2}{|c|}{ Control group $(n=18)$} & \multirow{2}{*}{$\begin{array}{l}\text { X2 } \\
\text { P-value }\end{array}$} \\
\hline & No. & $\%$ & No. & $\%$ & \\
\hline $\begin{aligned} & \text { Age } \\
&< 20 \\
& \geq 20- \\
&\end{aligned}$ & $\begin{array}{l}8 \\
10\end{array}$ & $\begin{array}{l}44.4 \\
55.6\end{array}$ & $\begin{array}{l}11 \\
7\end{array}$ & $\begin{array}{l}61.1 \\
38.9\end{array}$ & \multirow{2}{*}{$\begin{array}{l}1.003 \\
0.317\end{array}$} \\
\hline Mean + SD & \multicolumn{2}{|c|}{$20.9 \pm 2.01$} & \multicolumn{2}{|c|}{$19.4 \pm 2.17$} & \\
\hline $\begin{array}{l}\text { Sex } \\
\text { Male } \\
\text { Female } \\
\end{array}$ & $\begin{array}{l}12 \\
6\end{array}$ & $\begin{array}{l}66.7 \\
33.3\end{array}$ & $\begin{array}{l}9 \\
9\end{array}$ & $\begin{array}{l}50.0 \\
50.0\end{array}$ & $\begin{array}{l}1.02 \\
0.310\end{array}$ \\
\hline $\begin{array}{l}\text { Marital status } \\
\text { Married } \\
\text { Divorced or separated } \\
\text { Widowed } \\
\text { Single }\end{array}$ & $\begin{array}{l}1 \\
2 \\
0 \\
15\end{array}$ & $\begin{array}{l}5.6 \\
11.1 \\
0.0 \\
83.3\end{array}$ & $\begin{array}{l}1 \\
1 \\
0 \\
16\end{array}$ & $\begin{array}{l}5.6 \\
5.6 \\
0.0 \\
88.9\end{array}$ & $\begin{array}{l}0.366 \\
0.829\end{array}$ \\
\hline $\begin{array}{l}\text { Place of residence } \\
\text { Rural } \\
\text { Urban }\end{array}$ & $\begin{array}{l}7 \\
11\end{array}$ & $\begin{array}{l}38.9 \\
61.1\end{array}$ & $\begin{array}{l}5 \\
13\end{array}$ & $\begin{array}{l}27.8 \\
72.2\end{array}$ & $\begin{array}{l}0.13 \\
0.717\end{array}$ \\
\hline $\begin{array}{l}\text { Type of Faculty } \\
\text { Scientific } \\
\text { Theoretical }\end{array}$ & $\begin{array}{l}6 \\
12\end{array}$ & $\begin{array}{l}33.3 \\
66.7\end{array}$ & $\begin{array}{l}7 \\
11\end{array}$ & $\begin{array}{l}38.9 \\
61.1\end{array}$ & $\begin{array}{l}0.12 \\
0.728\end{array}$ \\
\hline
\end{tabular}

Table (1) shows that more than half of the intervention group (55.6\%) aged more than 20 years with a mean age of $20.9 \pm 2.01$ years, and more than one third of the control group (38.9\%) with a mean age of $19.4 \pm 2.17$ years. Concerning their sex, above two thirds of the intervention and control groups, $(66.7 \%$, and $50.0 \%$ respectively) were males. As regards to marital status, $83.3 \%$ of the intervention, and $88.9 \%$ of the control group were single compared to same percentages for both the intervention and control groups $(5.6 \%$ and $5.6 \%$ respectively) were married. It was observed that the majority of the intervention and control groups, $(66.7 \%$, and $61.1 \%$ respectively) were affiliated to theoretical faculties. Moreover, more than two thirds of the intervention group (66.7\%) and nearly three quarters of the control group $(61.1 \%)$ were from urban.

Table 2. Distribution of the studied sample according to their sources of hepatitis $\mathrm{C}$ information.

\begin{tabular}{|l|l|l|l|l|}
\hline \multirow{2}{*}{ Sources of hepatitis C information. } & \multicolumn{2}{|l|}{$\begin{array}{l}\text { Intervention } \\
\text { group }(\mathbf{n}=\mathbf{1 8})\end{array}$} & \multicolumn{2}{l|}{$\begin{array}{l}\text { Control } \\
(\mathbf{n}=\mathbf{1 8})\end{array}$} \\
\cline { 2 - 5 } & No. & $\%$ & No. & $\%$ \\
\hline Sources of information * & & & & \\
Family members & 6 & 33.3 & 5 & 27.8 \\
Friends or neighbors & 4 & 22.2 & 4 & 22.2 \\
Media (Television and Radio) & 7 & 38.9 & 8 & 44.4 \\
Physician & 3 & 16.7 & 4 & 22.2 \\
Nurse & 7 & 38.9 & 6 & 33.3 \\
Social networks/Websites & 8 & 44.4 & 12 & 66.7 \\
\hline
\end{tabular}

* Multiple answers.

Table (2): Reveals distribution of the studied sample according to their sources of hepatitis $\mathrm{C}$ information. Social networks and Websites, were reported as the main source of information about hepatitis $\mathrm{C}$ by less than half of the intervention group (44.4\%), and more than two thirds of the control group ( $66.7 \%)$, followed by $38.9 \%$ of the intervention group, and $44.4 \%$ of the control group who reported media like television and radio. Whereas, $38.9 \%$ of the intervention group, and $33.3 \%$ of control group indicated that nurses were their source of information about hepatitis C. However, family members were mentioned by $33.3 \%$ in intervention group, and $27.8 \%$ in control group. 
Table 3. Distribution of the studied groups according to their level of hepatitis C knowledge scores.

\begin{tabular}{|c|c|c|c|c|c|c|c|c|}
\hline \multirow{3}{*}{ Total knowledge scores } & \multicolumn{4}{|c|}{ Intervention group $(n=18)$} & \multicolumn{4}{|c|}{ Control group $(n=18)$} \\
\hline & \multicolumn{2}{|c|}{$\begin{array}{l}\text { Pre } \\
\text { program }\end{array}$} & \multicolumn{2}{|c|}{$\begin{array}{l}\text { Post } \\
\text { program }\end{array}$} & \multicolumn{2}{|c|}{$\begin{array}{l}\text { Pre } \\
\text { program }\end{array}$} & \multicolumn{2}{|c|}{$\begin{array}{l}\text { Post } \\
\text { program }\end{array}$} \\
\hline & No. & $\%$ & No. & $\%$ & No. & $\%$ & No. & $\%$ \\
\hline $\begin{array}{l}\cdot \text { Poor level of knowledge }(<50 \%) \\
\text { - Fair level of knowledge }(50 \%-<75 \%) \\
\text { - Good level of knowledge }(75 \%-100 \%)\end{array}$ & $\begin{array}{l}11 \\
5 \\
2\end{array}$ & $\begin{array}{l}61.1 \\
27.8 \\
11.1\end{array}$ & $\begin{array}{l}1 \\
6 \\
11\end{array}$ & $\begin{array}{l}5.6 \\
33.3 \\
61.1\end{array}$ & $\begin{array}{l}10 \\
6 \\
2\end{array}$ & $\begin{array}{l}55.6 \\
33.3 \\
11.1\end{array}$ & $\begin{array}{l}9 \\
5 \\
4\end{array}$ & $\begin{array}{l}50.0 \\
27.8 \\
22.2\end{array}$ \\
\hline Mean + SD & \multicolumn{2}{|c|}{$7.08 \pm 3.01$} & \multicolumn{2}{|c|}{$12.3 \pm 2.18$} & \multicolumn{2}{|c|}{$7.11 \pm 2.15$} & \multicolumn{2}{|c|}{$7.36 \pm 2.46$} \\
\hline $\begin{array}{l}\text { t-test } \\
\text { P1 }\end{array}$ & \multicolumn{4}{|c|}{$\begin{array}{l}4.25 \\
0.002 *\end{array}$} & \multicolumn{4}{|c|}{$\begin{array}{l}0.85 \\
0.311\end{array}$} \\
\hline $\begin{array}{l}\text { t-test } \\
\text { P2 }\end{array}$ & & & & & \multicolumn{2}{|c|}{$\begin{array}{l}0.79 \\
0.32\end{array}$} & \multicolumn{2}{|c|}{$\begin{array}{l}4.01 \\
0.003 *\end{array}$} \\
\hline ANOVA with Friedman's Test & \multicolumn{4}{|c|}{$16.951(0.000 *)$} & \multicolumn{4}{|c|}{$0.067(0.967)$} \\
\hline
\end{tabular}

Table (3) portrays that nearly two thirds of intervention group $(61.1 \%)$ in the pre program had poor knowledge level, followed by $27.8 \%$ of them had fair level. While, only $11.1 \%$ of them had good knowledge level, with mean score of $7.08 \pm 3.01$. On the other hand, more than half of the control group $(55.6 \%)$ had poor knowledge level, whereas nearly one third of them (33.3\%) had fair level, and more than one tenth of them (11.1\%) had good knowledge level, with mean score of $7.11 \pm 2.15$. An obvious improvement in the students' level of knowledge was noticed, as less than two thirds of intervention group $(61.1 \%)$ in post program had good level of knowledge. Remarkable decrease in percent of the students who had poor knowledge in post program (5.6\%) compared to one third (33.3\%) had fair knowledge level, with mean score of $12.3 \pm 2.18$. Significant differences was observed between intervention group at pre and 3 months post program implementation $(\mathrm{t} 1=4.25, \mathrm{P}=0.002)$.

In relation to control group, it was noticed that slight decline occurred $(50.0 \%)$ of the students who had poor knowledge in post program, followed by $27.8 \%$ of them had fair level and $22.2 \%$ of them had good knowledge level, with mean score of $7.36 \pm 2.46$ in post program. Significant difference was observed between intervention and control groups at 3 months post program evaluation $(\mathrm{t} 2=4.01, \mathrm{p}=0.003)$. Furthermore, the results of ANOVA Friedman's test indicated that there were statistical significant differences in responses in intervention group across the two stages $(\mathrm{p}=<0.000)$.

Table 4. The studied samples' mean SF-36 Generic Health-Related Quality of Life domains

\begin{tabular}{|c|c|c|c|c|c|c|}
\hline \multirow{2}{*}{ Variable } & \multicolumn{2}{|c|}{$\begin{array}{ll}\begin{array}{l}\text { Intervention } \\
(\mathrm{n}=18)\end{array} & \text { group } \\
\end{array}$} & \multirow{2}{*}{$\begin{array}{l}\text { Test of } \\
\text { sign. }\end{array}$} & \multicolumn{2}{|c|}{ Control group $(n=18)$} & \multirow{2}{*}{$\begin{array}{l}\text { Test of } \\
\text { sign. }\end{array}$} \\
\hline & $\begin{array}{l}\text { Pre } \\
\text { program }\end{array}$ & $\begin{array}{l}\text { Post } \\
\text { program }\end{array}$ & & $\begin{array}{l}\text { Pre } \\
\text { program }\end{array}$ & $\begin{array}{l}\text { Post } \\
\text { program }\end{array}$ & \\
\hline \multicolumn{7}{|c|}{ SF-36 generic Health-Related Quality of Life domains } \\
\hline Physical functioning & $12.56 \pm 2.01$ & $21.3 \pm 3.65$ & $0.002 *$ & $12.3 \pm 1.98$ & $13.1 \pm 2.13$ & 0.321 \\
\hline Role limitation-physical & $6.1 \pm 0.85$ & $9.1 \pm 2.31$ & $0.014 *$ & $6.5 \pm 0.79$ & $6.98 \pm 1.02$ & 0.562 \\
\hline Bodily pain & $3.1 \pm 0.45$ & $5.01 \pm 0.42$ & $0.036 *$ & $3.25 \pm 0.41$ & $3.33 \pm 0.51$ & 0.421 \\
\hline General health & $8.98 \pm 1.65$ & $12.3 \pm 1.32$ & $0.004 *$ & $9.01 \pm 0.88$ & $9.21 \pm 0.96$ & 0.336 \\
\hline Vitality & $5.1 \pm 1.02$ & $9.85 \pm 1.08$ & $0.006^{*}$ & $4.95 \pm 0.61$ & $5.10 \pm 0.75$ & 0.541 \\
\hline Social functioning & $3.11 \pm 0.85$ & $4.98 \pm 1.03$ & $0.035^{*}$ & $3.4 \pm 0.28$ & $3.5 \pm 0.36$ & 0.541 \\
\hline Role limitation-emotion & $4.6 \pm 0.74$ & $7.25 \pm 1.41$ & $0.005^{*}$ & $4.9 \pm 1.03$ & $5.11 \pm 0.98$ & 0.458 \\
\hline Mental health & $6.25 \pm 1.52$ & $12.3 \pm 1.47$ & $0.001 *$ & $6.11 \pm 0.87$ & $6.2 \pm 0.98$ & 0.471 \\
\hline
\end{tabular}

t: paired t-test

*Significant at $\mathrm{P} \leq 0.05$

Table (4) displays the distribution of the studied samples' mean SF-36 Generic Health-Related Quality of Life domains. Generally, it is clear that the intervention group at pre program saw themselves as sick. It was observed that they having nearly the same mean of Role limitation-physical and Mental health. Among eight domains of SF-36 generic quality of life measure, intervention group had mean of Physical functioning (PF) $12.56 \pm 2.01$, followed by General health $8.98 \pm 1.65$ and Vitality (VT) $5.1 \pm 1.02$, while Social functioning (SF) ranked last 3.11 \pm 0.85 . It was interesting that their mean scores was improved at post program stage to be $21.3 \pm 3.65$ for Physical functioning, followed by $12.3 \pm 1.47$ for Mental health and $12.3 \pm 1.32$ for General health, while $9.85 \pm 1.08$ for Vitality. Significant differences was observed between intervention group at pre and 3 months post program implementation regarding mean SF-36 Generic Health-Related Quality of Life domains. 
However, the control group at pre program had mean of Physical functioning (PF) $12.3 \pm 1.98$, followed by General health $9.01 \pm 0.88$ and Role limitation-physical $6.5 \pm 0.79$, while Bodily pain ranked last $3.25 \pm 0.41$. Additionally, their mean scores at post program stage was $13.1 \pm 2.13$ for Physical functioning, followed by $9.21 \pm 0.96$ for General health and $6.98 \pm 1.02$ for Role limitation-physical, while $3.33 \pm 0.51$ for Bodily pain. No significant differences was observed between the control group at pre and 3 months post program implementation regarding mean SF-36 generic Health-Related Quality of Life domains.

Table 5. The studied groups' mean of Disease Specific Health Related Quality Of Life domains

\begin{tabular}{|c|c|c|c|c|c|c|}
\hline \multirow{2}{*}{ Variable } & \multicolumn{2}{|c|}{$\begin{array}{ll}\begin{array}{l}\text { Intervention } \\
(\mathrm{n}=18)\end{array} & \text { group } \\
\end{array}$} & \multirow[t]{2}{*}{$\begin{array}{l}\text { Test of } \\
\text { sign. }\end{array}$} & \multicolumn{2}{|c|}{ Control group $(n=18)$} & \multirow[t]{2}{*}{$\begin{array}{l}\text { Test of } \\
\text { sign. }\end{array}$} \\
\hline & $\begin{array}{l}\text { Pre } \\
\text { program }\end{array}$ & $\begin{array}{l}\text { Post } \\
\text { program }\end{array}$ & & $\begin{array}{l}\text { Pre } \\
\text { program }\end{array}$ & $\begin{array}{l}\text { Post } \\
\text { program }\end{array}$ & \\
\hline \multicolumn{7}{|c|}{ Specific Health-Related Quality Of Life } \\
\hline Physical impact & $22.8 \pm 3.65$ & $39.5 \pm 3.88$ & $0.002 *$ & $21.3 \pm 3.52$ & $22.3 \pm 2.85$ & 0.236 \\
\hline Spiritual impact & $12.3 \pm 1.36$ & $16.5 \pm 4.21$ & $0.014 *$ & $11.8 \pm 1.24$ & $12.1 \pm 1.41$ & 0.421 \\
\hline Psychological impact & $14.3 \pm 2.1$ & $19.8 \pm 3.1$ & $0.011 *$ & $13.5 \pm 1.98$ & $13.9 \pm 2.01$ & 0.698 \\
\hline Social impact & $6.5 \pm 0.89$ & $10.1 \pm 1.36$ & $0.0035^{*}$ & $6.8 \pm 0.87$ & $7.1 \pm 0.77$ & 0.354 \\
\hline
\end{tabular}

$\mathrm{t}$ : paired t-test

*Significant at $\mathrm{P} \leq 0.05$

Table (5) shows the distribution of the study samples' mean disease specific health-related quality of life domains. Among hepatitis $\mathrm{C}$ students at the intervention group in pre program, physical impact was observed the highest mean of specific quality of life $22.8 \pm 3.65$, followed by psychological impact $14.3 \pm 2.1$, spiritual impact $12.3 \pm 1.36$ and the social impact was observed the lowest one $6.5 \pm 0.89$. It was exciting that their mean scores was improved at post program stage to be $39.5 \pm 3.88$ for physical impact, $19.8 \pm 3.1$ for psychological impact, $16.5 \pm 4.21$ for spiritual impact and 10.1 \pm 1.36 for social impact. Significant differences was observed between intervention group at pre and 3 months post program implementation regarding mean Specific Health-Related Quality Of Life domains.

Concerning to the control group mean disease specific health-related quality of life domains. Physical impact was the highest mean $21.3 \pm 3.52$ at pre program, followed by psychological impact $13.5 \pm 1.98$, spiritual impact $11.8 \pm 1.24$ and the social impact was observed the lowest one $7.1 \pm 0.77$. It was observed that 3 months post program implementation their mean scores was $22.3 \pm 2.85$ for physical impact, $13.9 \pm 2.01$ for psychological impact, $12.1 \pm 1.41$ for spiritual impact and $7.1 \pm 0.77$ for social impact. No significant differences was observed between the control group at pre and 3 months post program implementation regarding mean Specific Health-Related Quality Of Life domains.

Table 6. Distribution of the studied groups according to their total scores of hepatitis C self-management profile.

\begin{tabular}{|c|c|c|c|c|c|c|c|c|}
\hline \multirow{3}{*}{$\begin{array}{l}\text { Total scores of hepatitis } \mathrm{C} \text { self-management } \\
\text { profile }\end{array}$} & \multicolumn{4}{|c|}{ Intervention group $(n=18)$} & \multicolumn{4}{|c|}{ Control group $(n=18)$} \\
\hline & \multicolumn{2}{|c|}{ Pre program } & \multicolumn{2}{|c|}{ Post program } & \multicolumn{2}{|c|}{ Pre program } & \multicolumn{2}{|c|}{ Post program } \\
\hline & No. & $\%$ & No. & $\%$ & No. & $\%$ & No. & $\%$ \\
\hline Poor practice $(<50 \%)$ & 9 & 50.0 & 1 & 5.6 & 10 & 55.6 & 9 & 50.0 \\
\hline Fair $(50 \%-<75 \%)$ & 6 & 33.3 & 5 & 27.8 & 6 & 33.3 & 7 & 38.9 \\
\hline Good $(75 \%-100 \%)$ & 3 & 16.7 & 12 & 66.7 & 2 & 11.1 & 2 & 11.1 \\
\hline Mean + SD & \multicolumn{2}{|c|}{$31.2 \pm 6.25$} & \multicolumn{2}{|c|}{$41.0 \pm 8.3$} & \multicolumn{2}{|c|}{$28.1 \pm 5.85$} & \multicolumn{2}{|c|}{$29.3 \pm 6.01$} \\
\hline $\begin{array}{l}\text { t-test } \\
\text { P1 }\end{array}$ & \multicolumn{4}{|c|}{$\begin{array}{l}6.02 \\
0.0021 * \\
\end{array}$} & \multicolumn{4}{|c|}{$\begin{array}{l}1.36 \\
0.425 \\
\end{array}$} \\
\hline $\begin{array}{l}\text { t-test } \\
\text { P2 }\end{array}$ & & & & & \multicolumn{2}{|c|}{$\begin{array}{l}1.52 \\
0.312\end{array}$} & \multicolumn{2}{|c|}{$\begin{array}{l}7.1 \\
0.0001 *\end{array}$} \\
\hline ANOVA with Friedman's Test & \multicolumn{4}{|c|}{$\begin{array}{l}61.347 \\
.000^{*}\end{array}$} & \multicolumn{4}{|c|}{$\begin{array}{l}3.879 \\
.224\end{array}$} \\
\hline
\end{tabular}

t: Independent sample t-test

*Significant at $\mathrm{P} \leq 0.05$

$\mathrm{P} 1$ comparison between pre and 3 months post program implementation in each group.

P2 comparison between intervention and control groups at the same time.

In respect to students' total scores of hepatitis $\mathrm{C}$ self-management profile, a remarkable improvement was noticed among the intervention group through the stages of the study. Where, half of the students with hepatitis $\mathrm{C}$ had poor level of self-management in the pre program compared to only $5.6 \%$ of them in post program. Remarkably, students who had good level self-management were increased from pre program to post program (16.7\%, and $66.7 \%$ respectively), Table (6).

It was obvious that significant differences was observed among the intervention group between the two phases of the intervention $(\mathrm{t} 1=6.02, \mathrm{p}=0.0021)$. Significant difference was observed between intervention and control 
groups at 3 months post program evaluation $(\mathrm{t} 2=7.1, \mathrm{p}=0.0001)$. Furthermore, the results of ANOVA Friedman's test indicated that there were statistical significant differences in responses in intervention group across the two stages $(\mathrm{p}=<0.000)$.

Table 7. Distribution of the intervention group according to their satisfaction of the educational program

\begin{tabular}{|c|c|c|c|c|c|c|}
\hline \multirow{3}{*}{ Satisfaction of the educational program. } & \multicolumn{6}{|c|}{ Intervention group (n. 18) } \\
\hline & \multicolumn{2}{|c|}{ Neutral } & \multicolumn{2}{|c|}{ Agree } & \multicolumn{2}{|c|}{ Strongly Agree } \\
\hline & No. & $\%$ & No. & $\%$ & No & $\%$ \\
\hline $\begin{array}{l}\text { Program Objectives: } \\
\text { Clear } \\
\text { Meet needs and expectations }\end{array}$ & $\begin{array}{l}2 \\
3\end{array}$ & $\begin{array}{l}11.2 \\
16.7 \\
\end{array}$ & $\begin{array}{l}8 \\
6 \\
\end{array}$ & $\begin{array}{l}44.4 \\
33.3 \\
\end{array}$ & $\begin{array}{l}8 \\
9 \\
\end{array}$ & $\begin{array}{l}44.4 \\
50.0 \\
\end{array}$ \\
\hline $\begin{array}{l}\text { Program Contents: } \\
\text { Simple and easily understandable } \\
\text { Complete and comprehensive } \\
\text { Up to date } \\
\text { Suitable videos and images. }\end{array}$ & $\begin{array}{l}2 \\
1 \\
0 \\
3\end{array}$ & $\begin{array}{l}11.1 \\
5.6 \\
0.0 \\
16.7\end{array}$ & $\begin{array}{l}6 \\
5 \\
4 \\
5\end{array}$ & $\begin{array}{l}33.3 \\
27.8 \\
22.2 \\
27.8 \\
\end{array}$ & $\begin{array}{l}10 \\
12 \\
14 \\
10 \\
\end{array}$ & $\begin{array}{l}55.6 \\
66.7 \\
77.8 \\
55.6 \\
\end{array}$ \\
\hline $\begin{array}{l}\text { Language: } \\
\text { Clear and understandable }\end{array}$ & 4 & 22.2 & 3 & 16.7 & 11 & 61.1 \\
\hline $\begin{array}{l}\text { Program Design: } \\
\text { Interesting and attractive. } \\
\text { Easy to use. } \\
\text { Organized. } \\
\text { Interactive } \\
\end{array}$ & $\begin{array}{l}3 \\
2 \\
2 \\
4\end{array}$ & $\begin{array}{l}16.7 \\
11.1 \\
11.1 \\
22.2\end{array}$ & $\begin{array}{l}6 \\
5 \\
5 \\
4\end{array}$ & $\begin{array}{l}33.3 \\
27.8 \\
27.8 \\
22.2\end{array}$ & $\begin{array}{l}9 \\
11 \\
11 \\
10\end{array}$ & $\begin{array}{l}50.0 \\
61.1 \\
61.1 \\
55.6 \\
\end{array}$ \\
\hline $\begin{array}{l}\text { Program Usefulness: } \\
\text { Useful. } \\
\text { Motivating. } \\
\text { Adherence to use for long period. }\end{array}$ & $\begin{array}{l}1 \\
3 \\
2\end{array}$ & $\begin{array}{l}5.6 \\
16.7 \\
11.1 \\
\end{array}$ & $\begin{array}{l}6 \\
5 \\
3\end{array}$ & $\begin{array}{l}33.3 \\
27.8 \\
16.7 \\
\end{array}$ & $\begin{array}{l}11 \\
10 \\
13\end{array}$ & $\begin{array}{l}61.1 \\
55.5 \\
72.2\end{array}$ \\
\hline $\begin{array}{l}\text { Recommend for Using the Program: } \\
\text { Recommend for using the program by any hepatitis } \\
\text { C patient. }\end{array}$ & 2 & 11.1 & 4 & 22.2 & 12 & 66.7 \\
\hline Total Satisfaction scores & \multicolumn{3}{|l|}{ No. } & \multicolumn{3}{|l|}{$\%$} \\
\hline Satisfied $(75 \%-100 \%)$ & \multicolumn{3}{|l|}{18} & \multicolumn{3}{|l|}{100} \\
\hline Mean \pm S D & \multicolumn{6}{|c|}{$73.6 \pm 6.25$} \\
\hline
\end{tabular}

Regarding to students' satisfaction of the educational program, Table (7) reveals that more than one third $(44.4 \%)$ of the intervention group strongly agreed that the objectives were clear, whereas, $50.0 \%$ of them stated that the program objectives meet their needs and expectations. More than half $(55.6 \%)$ of the intervention group strongly agree that the program contents were simple and easily understandable. Completeness and comprehensiveness of program were mentioned by $66.7 \%$, up to date knowledge was mentioned by $77.8 \%$, and it contained suitable videos and images by $55.6 \%$. While, less than two thirds $(61.1 \%)$ of the intervention group strongly agreed that the language was clear and understandable. Regarding the program design, half of the students $(50.0 \%)$ strongly agreed that it was interesting and attractive, whereas, less than two thirds $(61.1 \%)$ of them stated that it was easy to use, the same percentages $(61.1 \%)$ of them reported that it was organized, and more than half $(55.6 \%)$ described it as interactive. Moreover, less than two thirds of students $(61.1 \%)$ strongly agreed about the usefulness of the program, and more than half of them mentioned that it was motivating them to practice selfmanagement. Though, the majority of them $(72.2 \%)$ decided that, they would adhere to use it for long period. Furthermore, the majority $(88.9 \%)$ of students were either agree or strongly agree on recommend using the program by any hepatitis $\mathrm{C}$ patient. Overall, the result revealed that, all students of the intervention group (100.0\%) were satisfied with the program with mean satisfaction score of $73.6 \pm 6.25$.

Table 8 . The correlation between the intervention group's satisfactions with interactive digital-based educational program and their hepatitis $\mathrm{C}$ self-management profile, knowledge and health-related quality of life score.

\begin{tabular}{|l|l|l|}
\hline \multirow{2}{*}{ Items } & $\begin{array}{l}\text { Program Satisfaction } \\
\text { Post program }\end{array}$ \\
\cline { 2 - 3 } & $\mathbf{r}$ & $\mathbf{p}$ \\
\hline Hepatitis C self-management profile score & 0.689 & $0.001^{*}$ \\
\hline Knowledge score & -0.062 & 0.705 \\
\hline Health-related quality of life score & 0.593 & $0.008^{*}$ \\
\hline
\end{tabular}

r: Pearson coefficient

*: Statistically significant at $\mathrm{p} \leq 0.05$

Table (8): portrays that statistical significant correlation was found between intervention group's satisfaction 
with the program and total score of self-management practices $(r=0.689, p=0.001)$, and Health-related quality of life score $(r=0.593, p=0.008)$ in post program. However, there was no statistical significant correlation between satisfaction with educational program and their knowledge in post program.

\section{Discussion}

Hepatitis $\mathrm{C}$ was one of the ultimate chronic infectious diseases in latest years. Egypt is provoked with a vast Hepatitis $\mathrm{C}$ virus (HCV) infection. It has the peak dominance of $\mathrm{HCV}$ in the world. Where HCV infection and its complications are among the primary public health challenges in the country. ${ }^{(32,33)}$ Liver mortality in Egypt grasps 40,000 per year, making $10 \%$ of total mortality, and comes second after heart diseases. ${ }^{(34)}$

Good self-management education is a vital for maintaining a healthy life for people with hepatitis $\mathrm{C}$, and provides the foundation to help them to take decisions with respect to their disease by encouraging the self-care behaviors. ${ }^{(35)}$ Furthermore, finding novel ways to enhance hepatitis $\mathrm{C}$ education is crucial for achieving optimal disease control, which can decrease the morbidity and mortality. ${ }^{(36)}$

Young adulthood is a critical time for the development and integration of lifelong disease management skills. It is important to focus education on core topics and tailor it to the individual needs and learning styles of the young people. ${ }^{(37)}$ Worldwide, youth are nearly two times more networked than the global population as a whole. In 2013 people ages 24 and younger accounted for $42.4 \%$ of the world's population but $45 \%$ of Internet users. ${ }^{(38)}$ The current study shows that nearly half of the study subjects who suffer from HCV are young adulthood and the most active users of Information and Communication Technologies. This result is reversed by Fábregas et al. (2013) ${ }^{(39)}$ who reported that the majority of patients who suffer from HCV are in middle adulthood.

The use of new digital health technology, which is becoming increasingly widespread, may help in delivering age-appropriate, quality-assured education for young people. Moreover, technology can extend the reach of education and support when primary care resources are insufficient or patient resources and access to care are limited. ${ }^{(40)}$ Thus, an Interactive Digital-Based education program such as website, e-mail, and whatApp were developed and used by the researchers to present the content of the program, thought to be an easily approachable means for better educating regarding HCV Self-management, Knowledge and improving Quality of Life.

The present study reveals that social networks and Websites, were reported as the main source of information about hepatitis $\mathrm{C}$ by less than half of the intervention group and more than two thirds of the control group, followed by media like television and radio. On the contrary, this was quite dissimilar from the study done on Pakistan (2016) ${ }^{(41)}$ to assess knowledge, attitude and practice regarding hepatitis b \& c, in which the first source of knowledge that reported by more than half of studied sample was mass media.

Deficiency of knowledge and awareness about Hepatitis $\mathrm{C}$ in the community habitually leads to distortion, missing of opportunities for prevention and treatment, and stigmatization of infected populations. ${ }^{(42)}$

After the implementation of educational program, the intervention group at the present study showed noteworthy improvement in their knowledge compared with the control group. Moreover, an obvious improvement was noticed between students of the intervention group at pre and post program regarding their level of knowledge, as nearly one tenth of intervention group in the pre program compared to less than two thirds of them in post program had good level of knowledge. This finding agreed with the study conducted at Ain Shams University (2015) that reported the educational program increases the samples' awareness and the level of knowledge about HCV infection. ${ }^{(43)}$ These results were in agreement with Estrella et al. (2012) ${ }^{(44)}$ study carried out on a large randomized control trial examining the effectiveness of an internet-based training module improving comprehension of chronic kidney disease (CKD) for internal medicine residents. Interestingly, researchers found that completion of the internet-based CKD education modules showed significant improvements in internal medicine residents' knowledge of CKD however, it is not understood if this increase in comprehension resulted in better patient care. So, the HCV self-management program being studied facilitates improved health outcomes by increasing HCV related knowledge, and teaching a variety of behavioral change skills.

As with other chronic illnesses, there are social, behavioral, and cognitive skills that patients can use to participate more effectively in the management of their HCV. ${ }^{(45)}$ These self-management strategies can help patients manage their symptoms, increase their functionality, make more informed decisions about treatment and potentially help prevent them from spreading the virus to others. ${ }^{(46)}$

Good self-management programs typically address (i) disease management, medications, general health; (ii) role management and (iii) emotional management. Patients learn to identify and prioritize their own problems, take appropriate action and enlist the support needed to solve these problems in collaboration with healthcare professionals and family. ${ }^{(47)}$

In respect to students' total scores of hepatitis $\mathrm{C}$ self-management profile, a remarkable improvement in the present study was noticed among the intervention group through the stages of the study. Where, half of the students with hepatitis $\mathrm{C}$ had poor level of self-management in the pre program compared to only $5.6 \%$ of them in post program. Remarkably, students who had good level self-management were increased from pre program to post program $\left(16.7 \%\right.$, and $66.7 \%$ respectively). These results were congruent with Mohsen, (2011) ${ }^{(48)}$ who showed a 
significant improvement of the practice of the studied sample of HCV family members regarding prevention and controlling cross infection of the disease after exposure to health education program. It was interesting to spot that the hepatitis $\mathrm{C}$ self-management program produced a number of important health benefits among patients with chronic hepatitis C infection. Moreover, Groessl et al., 2011, ${ }^{(49)}$ showed that the Hepatitis C Self-Management Program resulted in immediate improvements in patient outcomes at the end of a 6-week intervention period.

The HCV self-management program was produced significant improvements along a number of dimensions of HRQOL and other outcomes. Improving health-related knowledge is a main goal of most self-management programs. While increased knowledge may improve healthcare satisfaction in consumers, it is not always considered sufficient for producing changes in other health outcomes. ${ }^{(49)}$

Health related Quality Of Life (HRQOL) is a widespread term that transports an overall sense of wellbeing, including aspects of happiness and satisfaction with life as entire. It is broad and subjective rather than specific and objective. Long survival with HCV clues to diminish Health-Related Quality Of Life (HRQOL) even in the absence of clinically significant liver disease. Singularly, the impact of HCV give the impression to be most dramatic in social and physical function, general health and vitality, such as the effects of Hepatitis C on families, work environments, and on society as a whole. ${ }^{(50)} \mathrm{HCV}$ infection is connected with reduced Health-Related Quality of Life (HRQOL). The current study represents that the HCV self-management intervention improved scores on the energy/vitality subscale of the SF-36 of HRQOL post program implementation. The intervention group at pre program saw themselves as sickness. Which has also been implicated as one of the symptoms most likely to impact other aspects of HRQOL, such as physical, mental and/ or social functioning.

The present study reveals that the interactive digital-based education program was effective on all aspects of QOL among the intervention group. After the implementation of the program, the intervention group presented significant improvement in all items of disease-specific scale to measure HRQOL compared with the control group. These results are supported by Brito et al., study for individual treated at the Endocrinology Clinic of the Teaching Hospital of the Universidad Federal de Sergipe $(2016)^{(51)}$ aimed to assess QOL, knowledge about the disease and the attitude of individuals with type 2 diabetes before and after participation in an educational program and it reported a significant improvement in quality of life after participation in the educational program, particularly in the social relationships domain and decrease the suffering of living with diabetes. In addition to, there was statistically significant acquisition of knowledge. These findings coincided with the studies conducted on Chinese patients with chronic liver diseases at 2013, in which the study revealed that, the intervention was effective on all aspects of QOL among the experimental group. ${ }^{(52)}$ Additionally, Lam, J T. \& Salazar, L. (2016) reported the effects of hepatitis $\mathrm{C}$ on families, work environments, and on society as a whole, are remarkable. ${ }^{(53)}$

An important new finding was that self-management program participants experienced changes in generic quality of life often emerge more slowly as short-term improvements in disease-related knowledge and selfefficacy for managing one's chronic disease are practiced consistently over a longer period of time (Bandura, 2001). ${ }^{(54)}$

Over the past three years, an exciting combination of tools, ideas and networks have grasped. Now, this innovation have its' effect on the internet users which translated into a new approach to the use of online technology in supporting health, work and education, that has huge potential for positive change. ${ }^{(55)}$

Digital interventions (DIs) are programs that provide information and support (emotional, decisional, and/or behavioral) for physical and/or mental health problems via a digital platform (ie, interventions accessed via computer, mobile phone, or other handheld devices, including Web-based, desktop computer programs, or apps). $(56,57)$ DIs have been developed and used for numerous health issues including improving self-management of long-term conditions. It can potentially provide a convenient gateway for patients to access and receive tailored and private health information and services. The internet setting allows for increased access to the intervention and flexibility of use. Numerous systematic reviews have confirmed the potential effectiveness of DIs in improving health behaviors and health outcomes. ${ }^{(57,58)}$

The present study represents that more than one third of the intervention group strongly agreed that the educational program objectives were clear, whereas, $50.0 \%$ of them stated that the program objectives meet their needs, expectations and the program contents were simple and easily understandable. Completeness, comprehensiveness of program and up to date knowledge were mentioned by the majority of the students. These were in agreement with Robson (2009) ${ }^{(59)}$ who conduct a small study utilizing mixed methods examining webbased learning for primary care practitioners involving clinical guidelines and problem solving and judgment skills through discussion modules via the computer. The primary care providers reported enjoying this avenue of education and preferred the e-learning modules to traditional discussion-based learning due to the time and scheduling restraints of traditional organization discussion between colleagues. These were compatible with Pelayo-Alvarez, Perez-Hoyos, \& Agra-Varela (2013) ${ }^{(60)}$ who positively identifies that online education can influence positive practice changes and improve knowledge. Their study found increased understanding of the subject matter and more importantly, demonstrated clinical effectiveness with patients reporting better symptom control and global quality of life after their provider completed the online modules. This was contrary to Hale, 
Mirakian \& Day (2009) ${ }^{(61)}$ who led an experimental study investigating students' satisfaction and objective learning outcomes in respect to a pharmacology education through web-based lectures verses classroom instruction. Course satisfaction was high for both types of instruction, but students reported higher rates of self-perceived knowledge in the traditional classroom format.

Providing self-management information have been proposed as a promising mode of delivery for selfmanagement interventions. Wang et al., $2017^{(62)}$ reported that new advances in the use of mobile and wireless technologies and wearable devices for improving health care processes and outcomes provide promising options for low-cost, effective care and health promotion for patients with chronic diseases such as obesity and diabetes. It can be an effective tool for patients by helping facilitate their interactions with health care providers, other patients, and family members. Consequently, it appears that digital interventions hold potential in supporting the self-management of chronic diseases.

\section{Conclusion}

Interactive Digital-Based Education on Self- Management of Hepatitis C had positive impact on HCV outcomes including improvement in Hepatitis $\mathrm{C}$ knowledge, self-management practices and quality of life. In addition, it plays a significant role in improving Hepatitis $\mathrm{C}$ control, and motivates the students to adopt healthy lifestyle. Finally, the positive results noted for the participant join in intervention group demonstrated that Interactive Digital-Based education program was a useful tool to improve HCV Self-management, Knowledge and improving Quality of Life.

\section{Recommendations:}

- Use interactive technology to disseminate hepatitis $\mathrm{C}$ education messages to young people, including WhatsApp, Web Based education, etc.

- Develop University HCV Online platform for young people having Hepatitis C who need to receive ageappropriate Hepatitis $\mathrm{C}$ education.

- $\quad$ Public education and testing campaigns and other awareness activities are key strategies for improving public understanding and influencing health behaviors among populations most impacted by hepatitis $\mathrm{C}$.

\section{References}

1. Petruzziello et al., Global epidemiology of hepatitis $\mathrm{C}$ virus infection: an up-date of the distribution and circulation of hepatitis C virus genotypes, World J Gastroenterol 2016; September 14, 22(34): 7824-7840.

2. Younossi Z, Birerdinc A, Henry L., Hepatitis C infection: A multi-faceted systemic disease with clinical, patient reported and economic consequences, Journal of Hepatology 2016; vol. 65, S109-S119.

3. Mohamed et al., Hepatitis C virus: A global view. World J Hepatol 2015; 7(26): 2676-2680.

4. World Health Organization (WHO), Global Hepatitis Report 2017. Geneva: Switzerland: WHO; 2017.

5. Yarlott L, Heald E, Forton D, Hepatitis C virus infection, and neurological and psychiatric disorders - A review, Journal of Advanced Research 2017; 8, 139-148.

6. Rodger et al., Psychosocial and Neurocognitive Factors Associated With Hepatitis C - Implications for Future Health and Wellbeing, Front. Psychol. 2019; Volume 9, 1-6.

7. El-Ghitany EM, Hepatitis C Virus Infection in Egypt: Current Situation and Future Perspective, Journal of High Institute of Public Health 2019; 49(1):1-9.

8. Miller F, Abu-Raddad L, Evidence of intense ongoing endemic transmission of hepatitis C virus in Egypt, PNAS August 17, 2010; 107 (33) 14757-14762.

9. Gomaa et al., Hepatitis C infection in Egypt: prevalence, impact and management strategies, Hepatic Medicine: Evidence and Research 2017; 9: 17-25.

10. Kandeel et al., The prevalence of hepatitis C virus infection in Egypt 2015: implications for future policy on prevention and treatment, Liver Int. 2017; 37: 45-53.

11. Reker C, Islam M, Risk factors associated with high prevalence rates of hepatitis C infection in Egypt, International Journal of Infectious Diseases 2014; 25: 104-106.

12. Working Party: Chris Ford, Kate Halliday, Graham Foster, Charles Gore, Kate Jack, Nicola Rowan, Carola Sander-Hess, Sebastian Saville, Brian Thomson, Stephen Willott, Nat Wright and David Young. Guidance for the prevention, testing, treatment and management of hepatitis $\mathrm{C}$ in primary care, Royal College of General Practitioners, 1st Edition 2007. Available from: http://www.smmgp.org.uk

13. Cho H, Park E, Quality of Life of Chronic Hepatitis C Patients and Its Associated Factors, Osong Public Health Res Perspect 2017; 8(2):124-129.

14. Hassan E, Madian A, Hussein N, Effect ofAn Intervention Program On Health Related Quality Of Life (HRQOL) Among Hepatitis C Patients, IOSR Journal of Nursing and Health Science 2018; Volume 7, Issue 2 Ver. VIII, PP 28-40.

15. Ringehan M, McKeating J, Protzer U, Viral hepatitis and liver cancer, Phil. Trans. R. Soc. 2017; B 372: 


\section{4.}

16. Mehta G, Dusheiko G, Hepatitis C treatment and quality of life - You can't always get what you want, but you might get what you need, Journal of Hepatology 2015; vol. 63: 300-302.

17. Fawzy et al., Prevalence and risk factors of erectile dysfunction among chronic hepatitis $\mathrm{C}$ male patients treated with pegylated interferon- $\alpha$ and ribavirin, Egyptian Journal of Psychiatry 2015; 36:40-44.

18. Khanna D, Tsevat J, Health-related Quality of Life " An Introduction, Am J Manag Care 2007; 13:S218-S223.

19. Mittal P, Matreja P, Rao H, Khanna P, Prevalence and Impact of Hepatitis on the Quality of Life of Patients, Euroasian J Hepato-Gastroenterol 2015;5(2):90-94.

20. McGarragle K, Exploring Pain Self-Management Behaviours in Breast Cancer Survivors:A Mixed-Methods Study. Thesis degree of Master of Science. Institute of Medical Science, University of Toronto, 2017

21. Musekamp et al., Does improvement in self-management skills predict improvement in quality of life and depressive symptoms? A prospective study in patients with heart failure up to one year after self-management education, BMC Cardiovascular Disorders (2017) 17:51

22. Lavanchy D, Evolving epidemiology of hepatitis C virus, Clin Microbiol Infect 2011; 17: 107-115.

23. Groessl et al., The Hepatitis C Self-Management Program: Sustainability of Primary Outcomes at 1 Year, Health Education \& Behavior 2013; 40(6): 730-740.

24. World Health Organization (WHO), WHO Consolidated Guideline on Self-Care Interventions for Health: sexual and reproductive health and rights. Geneva: Switzerland: WHO; 2019.

25. Lupton $\mathrm{D}$, The digitally engaged patient: Self-monitoring and self-care in the digital health era, Social Theory \& Health 2013; Vol. 11, 3: 256-270.

26. SRI Education, 2018, Using Technology to Personalize Learning in K-12 Schools, SRI International, Menlo Park, CA. Available from: https://www.sri.com/work/publications/using-technology-personalize-learning-k12-schools

27. Krebbeks V, Cunningham V, Nurse-Managed Hepatitis C Clinic, Improving Quality of Life for Those in a Rural Area. Online Journal of Rural Nursing and Health Care 2013; 13(1).

28. Betty Irene Moore School of Nursing at UC Davis, New opportunities for nurses, 2019. Available from: https://www.ucdmc.ucdavis.edu/legal

29. Bashir A, Bastola D, Perspectives of Nurses Toward Telehealth Efficacy and Quality of Health Care: Pilot Study, 2019. Available from: https://www.ncbi.nlm.nih.gov/pmc/articles/PMC5993972/

30. Martino F. (1997) Assessment of the Health-Related Quality Of Life in Adult Chronic Hepatitis C Patients with Different Categories of Disease and Suggested Response to Intron. PHD Dissertation, Temple University.

31. Tawfik E. (2011). Impact of an Educational Program on Health Related Quality Of Life among Virus Hepatitis C Patients. PHD Dissertation, Alexandria University. High Institute of Public Health.

32. Estes et al., Economic Burden of Hepatitis C in Egypt: The Future Impact of Highly Effective Therapies, Alimentary Pharmacology \& Therapeutics 2015; 42(6), 696-706. Doi: 10.1111/Apt.13316.

33. Blach et al., Global Prevalence and Genotype Distribution of Hepatitis C Virus Infection In 2015: A Modeling Study. Lancet Gastro enteral hepatol. 2016; 2(3), 161-76.

34. El-Sayed M, The New National Strategy on Viral Hepatitis. Presentation In A Seminar Hosted By Al-Ahram Science Clubs, 2014. Http://www.Un.Org/Ga/Search/View_Doc.Asp?

35. Omisakin F, Ncama B, Self-care and self-management concepts: implications for self-management education Educational Research 2011; Vol. 2(12):pp. 1733-1737.

36. Redulla R, Reddy K, Faust T, Dudley-Brown S, Project P.E.A.C.H. (Pathway and Education Toward Adherence and Completion in Hepatitis C Therapy): a nurse-driven evidence-based protocol. Gastroenterol Nurs. 2015; 38(5):369-378.

37. Monaghan M, Helgeson V, Wiebe D, Type 1 diabetes in young adulthood, Curr Diabetes Rev. . 2015; 11(4):239-50.

38. UN, YouthStats: Information and Communication Technology. UN Web Services Section, 2018. https://www.un.org/youthenvoy/information-communication-technology/

39. Fábregas et al., Health Related Quality Of Life among Patients with Chronic Hepatitis C: A Cross-Sectional Study of Socio-Demographic, Psychopathological and Psychiatric Determinants. The Brazilian Journal of Infectious Diseases 2013; 17(6):633-9. Available: Https://Doi.Org/10.1016/J.Bjid.

40. Mesko B, Health IT and digital health: The future of health technology is diverse. J Clin Transl Res. 2018; 3(Suppl 3):431-434. Published 2018 Sep 8.

41. Babar F, Yar A, Muzammil J, Knowledge, attitude and practice regarding hepatitis b \& c among house officers — a study. Pakistan Oral \& Dental Journal 2016; Vol 36, No. 2.

42. Munusamy et al., Knowledge and awareness of hepatitis B among households in Malaysia: a communitybased cross-sectional survey. BMC Public Health. 2019; 19(1):47. doi:10.1186/s12889-018-6375-8

43. Faltas S, "Nursing Staffs' Knowledge and Practice regarding Prevention of Hepatitis C Virus Transmission in Hemodialysis Units” IOSR Journal of Nursing and Health Science 2018, vol. 7, no.5, pp. 35-47. 
44. Estrella M, Sisson S, Roth J, Choi M, Efficacy of an internet-based tool for improving physician knowledge of chronic kidney disease: an observational study. BMC Nephrol. 2012; 13:126. Doi: 10.1186/1471-2369-13126.

45. Evon D, Golin C, Ruffin R, Ayres S, Fried M, Novel patient-reported outcomes (PROs) used in a pilot and feasibility study of a Cognitive Behavioral Coping Skills (CBCS) group intervention for patients with chronic hepatitis C. Pilot and Feasibility Studies. 2018; 4(1):92.

46. Hutting N, Johnston V, Staal J, Heerkens Y, Promoting the Use of Self-management Strategies for People With Persistent Musculoskeletal Disorders: The Role of Physical Therapists. Journal of Orthopaedic \& Sports Physical Therapy. 2019; 49(4):212-5.

47. Garnett A, Ploeg J, Markle-Reid M, Strachan P, Self-Management of Multiple Chronic Conditions by Community-Dwelling Older Adults: A Concept Analysis. SAGE Open Nursing, 2018. https://doi.org/10.1177/2377960817752471

48. Mohsen et al., Effect of Nursing Management Protocol on Selected Side Effects of Interferon and Ribavirin among Hepatitis C Patients. Journal of American Science. 2011; 7(6). Available from: Http://www.Americanscience.Org.

49. Groessl et al., The hepatitis C self-management programme: a randomized controlled trial, Journal of Viral Hepatitis 2011; 18: 358-368. doi:10.1111/j.1365-2893.2010.01328.x

50. Younossi et al., Minimal Impact of Sofosbuvir and Ribavirin on Health Related Quality Of Life in Chronic Hepatitis C. Journal of Hepatology 2014; (60):741-47.

51. Brito G, Gois C, Zanetti M, Resende G, Silva J, Quality of life, knowledge and attitude after educational program for Diabetes, Acta Paul Enferm. 2016; 29(3):298-306.

52. Zhang et al., Effects of comprehensive intervention on health-related quality of life in patients with chronic hepatitis B in China. BMC Health Serv Res. 2013; 13:386.

53. Lam J, Salazar L, New Combination Antiviral for the Treatment of Hepatitis C. American Journal of Health System Pharmacy: AJHP: Official Journal Of The American Society Of Health -System Pharmacists 2016; 73(14): $1042-50$.

54. Bandura A, Social Cognitive Theory: An Agentic Perspective. Annual Review of Psychology 2001; 52(1):126.

55. Kontos E, Blake K, Chou W, Prestin A, Predictors of eHealth usage: insights on the digital divide from the Health Information National Trends Survey 2012. J Med Internet Res. 2014; 16(7):e172. doi:10.2196/jmir.3117

56. Alkhaldi et al., The effectiveness of technology-based strategies to promote engagement with digital interventions: a systematic review protocol. JMIR Res Protoc. 2015; 4(2):e47.

57. Alkhaldi et al., The Effectiveness of Prompts to Promote Engagement With Digital Interventions: A Systematic Review. J Med Internet Res 2016; 18(1):e6.

58. Burke et al., Current Science on Consumer Use of Mobile Health for Cardiovascular Disease Prevention. Circulation 2015; 132:1157-1213. DOI: 10.1161/CIR.0000000000000232

59. Robson J. Web-based learning strategies in combination with published guidelines to change practice of primary care professionals. Br J Gen Pract. 2009; 59(559):104-109.

60. Pelayo-Alvarez M, Perez-Hoyos S, Agra-Varela Y. Clinical effectiveness of online training in palliative care of primary care physicians. Journal of Palliative Medicine 2013; 16 (10):1188-1196. doi:10.1089/jpm.2013.0005.

61. Hale L, Mirakian E, Day D, Online vs. Classroom Instruction: Student Satisfaction and Learning Outcomes in an Undergraduate Allied Health Pharmacology Course. Journal of Allied Health 2009; 38(2): e-36-e42.

62. Wang et al., A Systematic Review of Application and Effectiveness of mHealth Interventions for Obesity and Diabetes Treatment and Self-Management. Adv Nutr 2017; 8:449-62; doi:10.3945/an.116.014100. 